\title{
Aerodynamic Synthesis of a Centrifugal Impeller Using CFD and Measurements
}

L.M. Larosiliere and G.J. Skoch

U.S. Army Research Laboratory

Lewis Research Center

Cleveland, Ohio

P.S. Prahst

NYMA, Inc.

Brook Park, Ohio

Prepared for the

33rd Joint Propulsion Conference and Exhibit

cosponsored by AIAA, ASME, SAE, and ASEE

Seattle, Washington, July 6-9, 1997

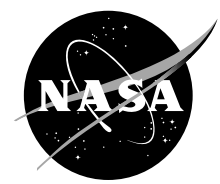

National Aeronautics and

Space Administration

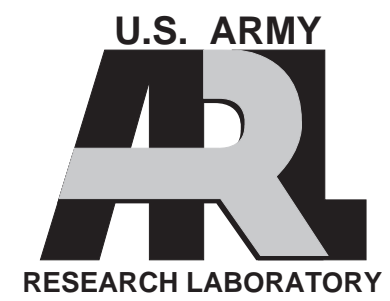




\title{
AERODYNAMIC SYNTHESIS OF A CENTRIFUGAL IMPELLER USING CFD AND MEASUREMENTS
}

\author{
L. M. Larosiliere ${ }^{1}$, G. J. Skoch ${ }^{1}$ \\ U.S. Army Research Laboratory \\ NASA Lewis Research Center \\ Cleveland, $\mathrm{OH} 44135$ \\ and \\ P. S. Prahst ${ }^{1}$ \\ NYMA Inc. \\ Brook Park, OH 44142
}

\begin{abstract}
The performance and flow structure in an unshrouded impeller of approximately 4:1 pressure ratio is synthesized on the basis of a detailed analysis of 3D viscous CFD results and aerodynamic measurements. A good data match was obtained between CFD and measurements using laser anemometry and pneumatic probes. This solidified the role of the CFD model as a reliable representation of the impeller internal flow structure and integrated performance. Results are presented showing the loss production and secondary flow structure in the impeller. The results indicate that while the overall impeller efficiency is high, the impeller shroud static pressure recovery potential is underdeveloped leading to a performance degradation in the downstream diffusing element. Thus, a case is made for a followon impeller parametric design study to improve the flow quality. A strategy for aerodynamic performance enhancement is outlined and an estimate of the gain in overall impeller efficiency that might be realized through improvements to the relative diffusion process is provided.
\end{abstract}

\section{INTRODUCTION}

Significant progress has been made in understanding impeller aerodynamic performance and also in predicting certain local flow details. A struggle is now ensuing to dislodge the last remaining deficits in performance for machines of low to moderate pressure ratios. Developers who place a premium on optimum performance are pursuing a synergistic approach based on a rational deployment of advanced aerodynamic, structural, and manufacturing methods. However, the question of what is the most effective strategy for improving both range and efficiency is still very much unresolved.
The most popular guide to impeller design is a diffusion parameter of some sort. Dean [1] discussed the influence of internal diffusion on impeller efficiency. His results, from calculations based upon two actual stages of medium and high pressure ratio, showed a trend of increasing efficiency with an increased overall diffusion ratio. Overall diffusion ratio is defined as the ratio of impeller inlet relative velocity, usually taken at the shroud, to impeller discharge relative velocity $\left(\mathrm{W}_{1} / \mathrm{W}_{2}\right)$. It was postulated by Dean that if an average overall diffusion ratio of 2.0 could be realized in the impeller, a significant increase in efficiency over conventional designs would follow. Kano et al. [2] presented results showing that in addition to the overall diffusion ratio, the rate of diffusion and maximum loading (i.e., 2D loading diagram) can significantly impact impeller peak efficiency and range. Kano's conclusions were based on boundary layer arguments supported by performance measurements on three machines of different design-intent loading distributions.

Moore et al. [3] used a three-dimensional viscous CFD method to examine the flow in a medium pressure ratio impeller. The CFD results, although not directly compared with measurements, showed several aspects of loss production in the impeller. Loss production was high over most of the shroud particularly within the clearance flow region. As expected from the impeller geometry, the internal diffusion process is likely to be very inefficient. In most measurements of impeller efficiency, the inefficiency of the internal diffusion process is hidden by the large centrifugal pressure rise. This nearly isentropic pressure rise is bought at the unavoidable expense of a high absolute exit kinetic energy; as a result the efficiency of the downstream process is greatly compromised. Vavra [4] offered an interesting commentary on the impeller internal diffusion process

\footnotetext{
${ }^{1}$ Aerospace Engineer

This paper is declared a work of the U.S. Government and is not subject to copyright protection in the United States.
} 
and he subsequently introduced a so called "wheel efficiency" to assess the quality and effectiveness of this process. In the calculations of Moore et al., a wheel efficiency of 60 percent was computed although the impeller polytropic efficiency was calculated to be 91 percent.

Currently, gaps in knowledge concerning impeller loss sources and magnitudes remain. For example, there is no definitive resolution of whether the existence and location of large regions of throughflow velocity deficit adversely impact loss generation within the impeller. Detailed measurements of the internal flow made by Krain [5], Hathaway et al. [6], and more recently Skoch et al. [7] are helping to fill some gaps. Moreover, application of CFD moored to these benchmark data sets can greatly increase the information content and also enhance our ability to make design choices. Hirsch et al. [8] calibrated their CFD method using Krain's data and performed numerical simulations guided by theoretical notions concerning secondary flow to assess the different contributions to secondary flows and their effect on the overall flow structure.

The intent of this paper is to synthesize the performance and flow structure in a moderate pressure ratio unshrouded centrifugal impeller through an application of Computational Fluid Dynamics (CFD) anchored to the measurements of Skoch et al. (Ref. 7). This synthesis is executed with an awareness of the prevailing impeller theoretical process models for internal diffusion, jet-wake flow, and secondary flow transport. Thus, a rational framework for a follow-on impeller parametric design study is established.

This paper is organized as follows. First, a description of the impeller design-intent and the experimental setup for the measurements is provided. Next, results of a data match between measurements and CFD are presented. Finally a discussion on the possibility of performance improvement is offered.

\section{IMPELLER DEFINITION AND EXPERIMENTAL SETUP}

The impeller was designed to produce a stage pressure ratio of $4: 1$ at a corrected mass flow of 4.54 $\mathrm{kg} / \mathrm{s}(10 \mathrm{lbm} / \mathrm{s})$ when coupled with a vane-island diffuser. A quasi-3D flow analysis developed in the early seventies was used to derive the flowpath and design-intent axisymmetric flow. The dimensionless specific speed is 0.60 with an impeller corrected tip speed of $492 \mathrm{~m} / \mathrm{s}(1615 \mathrm{ft} / \mathrm{s})$. At the aerodynamic design point, the intent was to keep the impeller loading roughly constant along the flowpath while doing most of the internal diffusion over the first 30$50 \%$ of the impeller meridional chord. The overall diffusion ratio along the shroud surface was set at about 1.4 with the goal of achieving an $83.3 \%$ totalto-static efficiency for the stage (i.e., impeller with vane-island diffuser and 90 degree bend) at a point with $8 \%$ minimum surge margin. Note that only the configuration consisting of the impeller discharging into a vaneless diffuser is of concern in this paper. Details of the aerodynamic and mechanical design including blade coordinates are given by McKain and Holbrook [9].

The impeller consists of 15 full blades and 15 splitter blades with 50 degrees of backsweep from radial. Splitter blade leading edges are located at 30 percent of full-blade chord and offset slightly toward the full-blade suction surface in order to produce an even flow split. The impeller surfaces are composed of straight-line elements from hub to shroud. A meridional cross-section of the flowpath, a view of the impeller, and some relevant geometric parameters are shown in Fig. 1. The exit diameter is $431 \mathrm{~mm}$ (16.986 in), and the impeller exit shroud clearance is 0.203 $\mathrm{mm}$ (0.008 inch).

The impeller was configured with a vaneless diffuser in a test-rig for overall performance evaluation and local flow diagnostics. Overall performance was derived from total pressure and temperature rakes located at a radius ratio of 1.18 (Fig. 1). Total pressure was measured using six, fourelement, total pressure rakes which were evenly spaced about the circumference of the vaneless diffuser. Four, three-element, total temperature rakes were located at the same radius ratio and were also spaced evenly about the circumference of the vaneless diffuser. Rake data were area averaged to determine overall pressure ratio and efficiency. The mass flow rate was determined using an orifice plate.

A single-component laser Doppler anemometer operating in the backscatter mode without frequency shifting was used to measure the velocity field within the impeller and vaneless diffuser. A full description of the anemometer, seeding system, and data reduction technique is given by Skoch et al. (Ref. 7 ). The uncertainty in the measured velocities ranged from less than 2 percent away from solid surfaces to 30 percent or more near the shroud and impeller surfaces. Additional local diagnostics were acquired using pneumatic probes. Static pressures were measured at several circumferential positions along the shroud from impeller leading edge to exit. The impeller discharge total pressure profile was measured with a constant blockage probe located at a radius ratio of 1.1 . 


\section{DATA MATCH BETWEEN CFD AND MEASUREMENTS}

Computational Method

The computational modeling of the impeller thermofluid-dynamic process was executed using the ADPAC computer program. Briefly, the ADPAC numerical methodology utilizes a finite volume, multigrid-based Runge-Kutta (four stages) timemarching algorithm to solve a time-dependent form of the 3-D Reynolds-averaged Navier-Stokes equations. Residual smoothing is applied after each stage to extend the stability domain of the algorithm. Turbulence closure is obtained by an adaptation of the Baldwin-Lomax mixing length model. Convective fluxes are handled using a second-order centered scheme stabilized with scalar artificial dissipation. The code employs a multiple-blocked structured mesh discretization which provides extreme flexibility for analyzing complex geometries. Further details about ADPAC are described by Hall et al. [10].

A five-block mesh was created using a simple algebraic grid generation technique. The first block represents part of the impeller passage extending from the full blade suction surface to the splitter pressure surface including the impeller entrance duct; the second block covers the remaining part of the impeller passage and entrance duct. Block three is the vaneless diffuser and extends from the impeller trailing edge to a radius ratio of 1.5 . These three blocks have a circumferentially periodic $\mathrm{H}-\mathrm{H}$ mesh structure. The fourth and fifth blocks have a $\mathrm{C}$ $\mathrm{H}$ mesh structure and occupy the space in the tip gap over the full and splitter blades respectively. The mesh consists of $161 \times 49 \times 33,161 \times 49 \times 33$, and $77 \times 49 \times 113$ points, in the throughflow, spanwise, and circumferential directions, for blocks 1, 2, and 3 respectively. Block 4 has $241 \times 9 \times 13$ points, with $9 \mathrm{H}$ lines over the full blade gap height and $13 \mathrm{C}$-lines across the blade profile. Similarly, over the splitter blade gap height, block 5 has $161 \times 9 \times 13$ points. Thus, the total number of mesh points is 994,057. Parts of the mesh are shown in Figure 2, including views of the tip clearance grid close to the splitter leading edge and the blunt trailing edges. The mesh spacings were controlled near solid surfaces to provide as much resolution as possible without overly disrupting the grid quality. ADPAC automatically switches to a wallfunction approximation for the wall shear stress when inadequate resolution exists.

The computational clearance gap paralleled that measured, which varied from the impeller inlet to exit. The measured running clearance distribution was $0.1524 \mathrm{~mm}$ (0.006 inch) near the leading edge, 0.61 $\mathrm{mm}$ (0.024 inch) near mid chord, and $0.203 \mathrm{~mm}$ (0.008 inch) near the trailing edge. In order to avoid backflow at the outlet boundary of the computational domain, the outlet portion of the vaneless diffuser was contracted. At the inlet, the measured total pressure and temperature profiles along with zero swirl angle were specified. A constant static pressure boundary condition was prescribed at the exit of the computational domain.

\section{Overall Performance}

The overall performance from inlet to a radius ratio of 1.18 at the design speed (21789 rpm) is shown in Figure 3. Both pressure ratio and adiabatic efficiency are adequately predicted at the near-design point flow rate of $4.57 \mathrm{~kg} / \mathrm{s}(10.06 \mathrm{lbm} / \mathrm{s})$ and also for higher flow rates. However, the comparison is not as good at the flow rate less than design. No attempt was made to predict the complete characteristic including the stalling flow since the goal was to closely match the performance near the design flow rate. Near the design point, the CFD predicted flow rate is $4.70 \mathrm{~kg} / \mathrm{s}(10.35 \mathrm{lbm} / \mathrm{s})$ with a pressure ratio of 4.16 and an adiabatic efficiency of 87.7 percent. The predicted efficiency is higher near the design flow by about $1 \%$ and tends to be higher at the lower flow because of the higher predicted pressure ratio. A comparison of the measured and CFD predicted total temperature rise showed very close agreement. Thus, the higher pressure ratio is due to lower predicted losses rather than higher work input.

\section{$\underline{\text { Local Diagnostics }}$}

The computed and measured circumferentially-averaged static pressure distributions along the shroud are presented in Figure 4 for the near design point operating condition. Also shown, is the isentropic static pressure ratio due to centrifugal static enthalpy rise along the shroud. This is calculated by defining an intermediate state (U) such that

$$
h_{U}-h_{1}=\frac{U_{2}^{2}-U_{1}^{2}}{2}
$$

Where $U$ is the wheel speed and $h$ is the static enthalpy. For this intermediate state (U), an isentropic static pressure ratio is obtained from,

$$
\frac{P_{U}}{P_{1}}=\left(\frac{h_{U}}{h_{1}}\right)^{\frac{\gamma}{\gamma-1}}
$$

The measurements represent the time-mean or steady pressure distribution along the shroud while the computations correspond to a simple area-average of the CFD results. Close agreement between CFD and measurements is seen. However, near the impeller 
trailing edge, the isentropic centrifugal static pressure rise is much higher than either that from CFD or measurements. This point will be addressed in a later discussion.

The measured and computed spanwise distributions of circumferentially-averaged total pressure at a radius ratio of 1.1 are shown in Figure 5 for the near design point operating condition. Also included for comparison, is the computed total pressure distribution at a radius ratio of 1.18. A good match is observed between CFD and measurements. Most of the discrepancies are near the shroud suggesting perhaps less mixing in the CFD model of the clearance flow than is implied by the measurements.

Figure 6 shows a comparison between the quasi-throughflow velocity distribution derived from CFD and that measured with the laser anemometer on three cross-flow planes (see Fig. 1) for the near design-point flow rate. The quasi-throughflow velocity distribution was extracted from the velocity normal to the spanwise grid lines employed for the CFD model. This velocity is normalized with the impeller tip speed. The measurements were converted from their raw form to a format similar to the CFD results. It should be noted that the laser probe has a restricted range of spatial coverage and is unable to survey the entire span or resolve the fine details near solid surfaces. The quasi-throughflow velocity derived from the measurements represents data collected over the entire impeller circumference and then ensemble averaged to yield the velocity distribution in a single impeller passage. Nevertheless, the intent here is to ascertain whether or not the gross features of the impeller internal flow structure are captured by the CFD model.

The CFD results of quasi-throughflow velocity are presented for two different clearance gap distributions: a constant tip gap of $0.203 \mathrm{~mm}(0.008$ inch), and the measured distribution previously given. As seen from Figure 6, the CFD results are in good agreement with the measurements for the first two cross-sections presented. Near the splitter leading edge at $30 \%$ chord, a small region of relatively lower throughflow velocity is observed on either side of the splittered passage along the shroud. This is due to scraping of the leakage flow by the splitter leading edge. At 52\% chord, a distinctive low throughflow region situated near the shroud of impeller passage 1 is evident. The pitchwise location of the center of this low throughflow region is clearly affected by the clearance gap as can be observed from the CFD results. Proceeding to $96 \%$ chord, the CFD results, although acceptable in the large, differ from the measurements in terms of fine details. These differences may be due to deficiencies in the turbulence model or possibly numerical discretization errors. However, it is also possible that the measurement uncertainties at this location are higher than those of the CFD model. These issues will be clarified in the near future using more refined measurement techniques and a higher fidelity CFD model.

The computed flow structure is very different within the two sides of the splittered passage at $96 \%$ chord. In addition, a high throughflow region is observed near both the suction and pressure surfaces of the leading side of the splittered passage (i.e., passage 1). Although the classical jet-wake flow structure is not evident, a structure dominated by the appearance of two large pools of low throughflow velocity fluid is clearly observed. Most of the essential flow features are deemed adequately represented by the CFD model. Also, the present CFD results using ADPAC are similar to those presented by Skoch et al. (Ref. 7) using a commercial CFD code.

\section{DISCUSSION}

Having instituted a reasonable data match between CFD and measurements, the question as to the possibility for performance improvements is very appropriate. Herein, this question is tackled by using the CFD model to explore the evolution of irreversibilities and secondary flows within the impeller. Only the CFD results using the actual shroud clearance distribution are interrogated. In addition, the measurements are used to extract the overall performance from inlet to the impeller trailing edge (i.e., separating impeller performance from measured overall performance) in terms of total pressure ratio, adiabatic efficiency, and wheel efficiency. This information is synthesized to establish the possibility for performance improvements by flow control.

\section{Irreversibilities and Flow Structure}

The principal losses in an unshrouded impeller flow process are due to friction and mixing linked to the dissipation of relative kinetic energy, shear work at the shroud, and clearance flow. Figure 7 shows the development of the entropy field ( $\mathrm{s}=$ $\left.[1 /(\gamma-1)] \ln \left(p \rho^{-\gamma}\right)\right)$ within the impeller and vaneless diffuser discharge as derived from the CFD results at the near design flow operating condition. Close to the impeller leading edge, at $10 \%$ chord, the high entropy region is small and confined to the solid surfaces. Near the splitter leading edge, at $30 \%$ chord, a high entropy region is beginning to accumulate along the shroud. Also evident is the almost isentropic hub endwall. Proceeding downstream to $52 \%$ chord, 
further accumulation of two high entropy cores can be observed near the shroud. Note that the highest entropy region is situated near the juncture of the shroud and the full blade pressure surface. Subsequently, approaching the trailing edge at $70 \%$, $84 \%$, and $96 \%$ chord, the high entropy regions near the shroud exhibit a rapid diffusion toward the center of the passages. Referring to Figure 6, it can be observed that the high entropy cores correspond to pools of low throughflow velocities within the impeller.

At the impeller discharge for a radius ratio of 1.01, high entropy regions are observed near the splitter and full blade trailing edges. The thick trailing edges contribute to a dump loss. Also noted is the rapid mixing between high and low entropy regions when moving downstream to higher radius ratios. This is further illustrated by the development of the computed mass-averaged entropy change $\left(\Delta \mathrm{s} / \mathrm{R}_{\mathrm{G}}\right)$ within the vaneless space presented in Figure 8. A very rapid rate of entropy rise is observed from the impeller discharge to a radius ratio of about 1.04 which is consistent with a measure of the streamwise impeller wake decay reported by Skoch et al. (Ref. 7). Thereafter, a much milder rate of entropy rise is seen. Beyond a radius ratio of 1.18 , the entropy field is nearly uniform.

The entropy distributions shown in Figure 7 follow closely the secondary flow transport within the impeller. It has been established by many investigators (see for example Ref. 6) that the main mechanism for the accumulation of low momentum fluid within the impeller is the spanwise transport of boundary layer fluid along the passage surfaces. The ultimate location of pools of low momentum fluid results from a balance between secondary flows induced by streamwise vorticity, corner vortices, and the clearance gap. An expression can be derived (see Zangeneh et al. [11]) from classical secondary flow theory to describe the generation of impeller secondary flows. This expression is:

$$
\vec{W} \cdot \nabla\left(\vec{W} \cdot \vec{\omega}_{r e l}\right)=2 \vec{\omega}_{r e l} \cdot(\vec{W} \cdot \nabla) \vec{W}+\vec{\omega}_{r e l} \cdot(2 \vec{\Omega} x \vec{W})
$$

where $\mathbf{W} \backslash|\mathbf{W}| \cdot \omega_{\text {rel }}$ represents the local streamwise component of relative vorticity (e.g., relative helicity) and $\Omega$ is the rotational velocity. According to this equation, secondary flows are generated when there exists a component of acceleration due to either streamline curvature $(\mathbf{W} . \nabla \mathbf{W})$ or Coriolis force $(\mathbf{2} \Omega \times \mathbf{X W})$ in the direction of relative vorticity $\left(\omega_{\text {rel }}\right)$. The first term is responsible for the passage vortices due to flow turning in either meridional or blade-toblade planes, while the second term is due to Coriolis acceleration. Flow turning and streamline curvature in the blade-to-blade plane generate secondary flows due to vorticity in the endwall boundary layers. Meridional curvature induces secondary flows due to vorticity in blade surface boundary layers. The contribution from Coriolis acceleration is effective if an axial boundary layer gradient exists as is usually the case in the radial portion of the impeller. Other vortices having a local influence on the flow, such as the horseshoe, corner, and clearance vortices, are not described by the above expression.

Secondary flow distributions were obtained from the CFD results by first extracting a primary flow defined along the local direction of the streamwise oriented mesh lines and then calculating a vector having components normal to this primary flow on several cross-flow planes. This is displayed in Figure 9 for the near design flow operating condition. Note that every other point has been removed for clarity. Also shown is the normalized relative helicity distribution which gives a direct measure of streamwise vorticity. Near the impeller inlet, at $10 \%$ chord, there is some indication of spanwise outward flow on both blade surfaces and the development of a small scraping vortex at the shroud-pressure surface corner. Proceeding downstream to $30 \%$ chord, near the splitter leading edge, a large clockwise vortex generated by the meridional curvature can be observed along the pressure surface of the full blade. In addition, a small leakage vortex interacting with this pressure surface vortex is noticed near the splitter suction surface similar to observations made by Hathaway et al. (Ref. 6). In the suction surface part (passage 1) of the splittered passage, details of the secondary flow structure are obscured by incidence loading effects near the splitter leading edge. At $52 \%$ chord, strong blade vortices along both suction (counterclockwise vortex or negative helicity) and pressure (clockwise vortex or positive helicity) surfaces can be seen. There is a nearly symmetric pattern in impeller passage 1 (i.e., near full blade suction surface) while in passage 2 , the pressure side of the blade surface vortex is reinforced by a growing shroud-side passage vortex (due to blade loading). The helicity chart indicates that the leakage flows (negative helicity) and the spanwise flows along the pressure surfaces (positive helicity) of the two passages collide near the blade tip. This may explain the existence of high entropy regions near the shroudpressure side. Continuing to $70 \%$ and $84 \%$ chord, further development of the passage vortex and its interaction with the blade surface vortices and the leakage flow near the splitter suction surface can be observed. In addition, between $84 \%$ and $96 \%$ chord, the shroud passage vortex, mainly contributed by the blade loading and augmented by the Coriolis vortex, 
is dominating. The leakage vortex can be observed near the shroud-suction side corner of the full blade.

From Figures 7, 8, and 9, an understanding of the generation and accumulation of low energy fluid within the impeller can be gained. The picture that develops is one in which energy dissipation within blade surface boundary layers and shear work along the shroud generate low relative kinetic energy fluid. This fluid is transported by the prevailing secondary and leakage flows which results in the development of a pool of low relative kinetic energy fluid at the impeller exit. At the impeller discharge, the dump loss from the thick trailing edges along with this pool of low relative kinetic energy fluid begin to rapidly mix under the actions of turbulent viscous stresses and the residual secondary flows generated within the impeller. Note that the role of unsteady fluctuations (e.g., vortex shedding) in this mixing process is unclear and unaccounted for in the CFD model. Additional energy dissipation occurs due to this mixing and frictional forces along the stationary endwalls of the vaneless diffuser.

Blade Loading and Impeller Static Pressure Recovery Viscous dissipation in shear layers is proportional to the wetted area and the cube of the local "free-stream" velocity. The free-stream velocity is related to the local surface static pressure or blade loading. Figure 10 presents the loading distributions derived from the CFD model at hub, mean, and tip. The static pressures are normalized with the inlet total pressure. At the hub surface, the loading is nearly zero over the first $30 \%$ of chord. From $30 \%$ chord to the trailing edge, a gradual increase in loading can be seen in both parts of the splittered passage. Note that the loading distribution is similar in both parts of the splittered passage except differences close to the splitter leading edge. The loading diagram at mid-span shows an almost uniform loading along the chord except for large variations locally near the splitter leading edge. This is consistent with the design intent for this impeller. For the tip section, a nearly uniform loading distribution is also seen. Aft of the splitter leading edge, a noticeable difference is observed in the loadings of the two sides of the splittered passage. This difference is due to the leakage flow.

Referring to Figure 4, the static pressure rise due to the centrifugal acceleration, assumed to be reversible, is higher at the impeller trailing edge than the circumferentially-averaged (area averaged) static pressure obtained from either CFD or measurements. Assuming negligible impact of unsteady static pressure fluctuations in the relative frame, Figure 4 implies that inadequate (i.e., less than what is required to counterbalance losses along the shroud) relative diffusion is achieved along the impeller shroud. Hence, the static pressure recovery potential of this impeller appears to be underdeveloped. Currently, most impeller design systems (see Japiske and Baines [12] for example) are structured similar to the well known jet-wake flow model first proposed by Dean [13] but have been further developed and extended with proprietary correlations derived from test data. This model assumes the flow to be partitioned into two zones at the impeller trailing edge: an isentropic core or jet and a viscous wake. Impeller performance is determined by a diffuser-like correlation defining the impeller exit static pressure recovery as a function of an effective measure of overall diffusion ratio similar to what has been reported by Schumann et al. [14]. However, this type of correlation does not account for the diffusion rate which is known to also play a critical role in establishing the peak pressure recovery. The isentropic assumption, the static pressure recovery relationship, and a slip factor rule completely define the impeller exit jet aerodynamic state. Ad-hoc modifications are made to account for the presence of splitters. The wake is often assumed to have the same exit flow angle as the impeller exit metal angle. This assumption along with the area and losses allow a definition of the impeller exit wake aerodynamic conditions. A mixing model for jet and wake is then used to arrive at the impeller exit mixed out aerodynamic state.

As shown in Figure 4, there is a substantial static enthalpy rise due to the centrifugal acceleration. This static enthalpy rise can be considered to occur reversibly. Thus, it is appropriate when considering the efficiency of the impeller to remove the centrifugal enthalpy rise from consideration by defining an intermediate state (U) and a wheel efficiency such that

$$
\eta_{w}=\frac{h_{2, i s}-h_{U}}{h_{2}-h_{U}}
$$

where $h_{2, \text { is }}$ is the isentropic static enthalpy rise at the impeller trailing edge. The wheel efficiency thus measures the quality and effectiveness of the relative diffusion (e.g., $\mathrm{h}_{2}-\mathrm{h}_{\mathrm{U}} \sim 0.5\left(\mathrm{w}_{1}{ }^{2}-\mathrm{w}_{2}{ }^{2}\right)$ ) process within the impeller. For the design speed, the measured shroud static pressure at the impeller exit and the total temperature measured at a radius ratio of 1.18 were used to estimate the impeller performance at several corrected flows from choke to stall. This was done using conservation of mass and energy assuming no aerodynamic blockage at the impeller exit. Thus, the impeller performance from inlet to trailing edge in terms of total pressure ratio, adiabatic efficiency (total-total), and wheel efficiency are shown 
in Figure 11. The scatter shown in Figure 11 is due to variations in the rig inlet total pressure used for determining performance sensitivity to Reynolds number changes. As originally noted by Vavra (Ref. 4), negative wheel efficiencies are caused by very low static pressure rise and do not imply negative entropy production. A peak impeller adiabatic efficiency of nearly $94 \%$ is estimated, whereas the peak wheel efficiency is about 20\%. These estimates were corroborated by the CFD model which predicted an impeller adiabatic efficiency of $91 \%$ at zero wheel efficiency as compared to a value of nearly $92 \%$ shown in Figure 11 for the near design operating point. Thus, there exists a possibility for significant performance improvement through an aerodynamic redesign of this impeller. Such a redesign should be executed not only to increase the impeller efficiency by reducing the entropy rise, but also to produce more uniform flow conditions at the impeller discharge. It might then be possible to reduce mixing losses and enhance the effectiveness of the downstream diffusing element.

\section{Impeller Aerodynamic Redesign Strategy}

The measured adiabatic efficiency at a radius ratio of 1.18 near the design flow rate is $86.7 \%$ while at the impeller discharge, a peak adiabatic efficiency close to $94 \%$ is inferred from the measurements at the design speed. Thus, it seems possible to achieve a significant gain in efficiency at the same stall margin if the root causes of this efficiency deficit are attacked. An efficiency audit which accounts for a projected increase in wheel efficiency, reduced clearance gap, and lower mixing losses is attempted based on the results presented. The results from Figure 11 augmented with other data at various shroud clearance levels are trans-plotted in Figure 12. This provides an estimate of the sensitivity of impeller efficiency to changes in wheel efficiency. A linear least squares fit is shown going through most of the data. Clearly if the wheel efficiency could be increased by $40 \%$ to an achievable level of $60 \%$ (see Ref. 4), about a $2 \%$ gain in adiabatic efficiency may be realized for this impeller. It seems reasonable based on Figure 8 that another $2 \%$ could be gained by improving flow uniformity to reduce mixing losses downstream of the impeller since the losses in this region are currently estimated to cost about $5 \%$ in overall efficiency at the near design operating point. Hence, a net gain of $4 \%$ in adiabatic efficiency is estimated for this impeller at the aerodynamic design point.

A principal cause of stagnation pressure losses is the failure of the impeller to achieve its maximum static pressure recovery, which inevitably leads to stagnation pressure mixing losses after the impeller. This is supported by the low estimated wheel efficiency. Aerodynamic synthesis of the impeller points to the following remedies leading to efficiency gains: better shroud static pressure recovery, secondary flow control, and reduced leakage flows by reducing the shroud clearance gaps. Static pressure recovery can be increased by using better flow quality concepts. Improvements in both the amount and rate of internal diffusion, hence increased static pressure recovery, may be obtained by proper endwall contouring and the use of three-dimensional or sculptured blades to control the flow. As previously discussed, there exist strong blade surface secondary flow vortices within the impeller. These secondary flows can be controlled and possibly suppressed using carefully designed 3D blade geometries similar to what has been done by Zangeneh et al. [15]. In addition, increased diffusion and 3D blades will lead to reduced viscous dissipation within the impeller itself.

Using the ADPAC code coupled to a geometry generation scheme for the impeller, a systematic parametric evaluation of the impact of certain impeller design variables on performance can be executed. This will lead to a correlation between impeller geometry, internal flow, and performance. Enabling inverse design and optimization techniques can later be deployed.

\section{SUMMARY}

A good match between CFD and measurements was obtained for an unshrouded centrifugal impeller of approximately 4:1 pressure ratio. Significant discrepancies between the velocity measurements and CFD did not appear until the purely radial part of the impeller where they are attributed to inadequate turbulence modeling, numerical discretization errors, and measurement uncertainties. Overall, the CFD gave a good prediction of the measured performance and resolved enough of the local flow details to accord it a prominent position in a design optimization cycle.

Aerodynamic synthesis of CFD results and measurements using laser anemometry revealed pools of low relative kinetic energy fluid within the impeller passage. The origins of this fluid were deduced to be from blade boundary layer material, leakage flow, and fluid having been subjected to shear work along the stationary shroud. Strong secondary and leakage flows generated within the impeller carry this fluid within the blade passage to form the observed flow structure.

Although the peak impeller efficiency of nearly $94 \%$ at the design speed was quite high, very low wheel efficiencies on the order of $20 \%$ or less 
were estimated from the measurements. As defined, wheel efficiency gives a measure of the effectiveness and aerodynamic quality of the relative diffusion process. Thus, the impeller shroud static pressure recovery potential was judged to be underdeveloped. A $2 \%$ increase in impeller efficiency is projected if the wheel efficiency were to be increased to a more reasonable value such as $60 \%$. Additional gains can be derived from a reduction of the discharge flow distortion which will reduce mixing losses that are incurred downstream of the impeller. Given the low initial value of wheel efficiency in this impeller, a case was made for significant performance improvements through the use of flow control concepts such as 3D sculptured blades and endwall contouring.

A follow-on parametric study of the impact of certain design variables on internal flow structure and performance of this impeller can be reliably performed using the ADPAC code. The ensuing correlation between geometry, flow structure, and performance will facilitate the ultimate goal of improved impeller and stage aerodynamic performance.

\section{REFERENCES}

1. Dean R., "On the Unresolved Fluid Dynamics of the Centrifugal Compressor," Advanced Centrifugal Compressors, 1971, ASME Publications.

2. Kano F., Tazawa N., Fukao Y., "Aerodynamic Performance of Large Centrifugal Compressors," ASME Paper 82-GT-17.

3. Moore J., Moore J. G., Timmis, P. H., "Performance Evaluation of Centrifugal Compressor Impellers Using Three-Dimensional Viscous Flow Calculations," J. of Engineering for Gas Turbines and Power, Vol. 106, pp. 475-481(1984).

4. Vavra , M. H., "Basic Elements of Advanced Design of Radial-Flow Compressors," AGARD Lecture Series No. 89 on "Advanced Compressors," 1970.

5. Krain H., "A Study on Centrifugal Impeller and Diffuser Flow," Transactions of the ASME, Vol. 103, pp. 688-697(1981).

6. Hathaway M. J., Chriss R. M., Wood J. R., Strazisar A. J., "Experimental and Computational Investigation of the NASA Low-Speed Centrifugal Compressor Flow Field," ASME J. of Turbomachinery, Vol. 115, pp. 527-542 (1993).

7. Skoch G. J., Prahst P. S., Wernet M. P., Wood J. R., Strazisar A. J., "Laser Anemometer Measurements of The Flow Field in a 4:1 Pressure Ratio Centrifugal Impeller," ASME Paper 97-GT-342

8. Hirsch Ch., Kang S., Pointel G., "A Numerically Supported Investigation of The 3D Flow in
Centrifugal Impellers," ASME Paper 96-GT-151, and, ASME Paper 96-GT-152.

9. McKain T. F., Holbrook G. J., "Coordinates for a High Performance 4:1 Pressure Ratio Centrifugal Compressor," NASA Contract NAS 3-23268 (1982), (to be published as a NASA CR).

10. Hall E. J., Delaney R. A., "Investigation of Advanced Counterrotation Blade Configuration Concepts for High Speed Turboprop Systems: Task VII - ADPAC User's Manual," NASA CR 195472 (1995).

11. Zangeneh M., Dawes W. N., Hawthorne W. R., "Three-Dimensional Flow in Radial-Inflow Turbines," ASME Paper 88-GT-103.

12. Japiske D., Baines N. C., Introduction to Turbomachinery, Concepts ETI and Oxford University Press (1994).

13. Dean R. C., "The Fluid Dynamic Design of Advanced Centrifugal Compressors," Creare, TN-185 (1974).

14. Schumann L. F., Clark D. A., Wood J. R., "Effect of Area Ratio on the Performance of a 5.5:1 Pressure Ratio Centrifugal Impeller," NASA TM 87237 (1986). 15. Zangeneh M., Goto A., Takemura T., "Suppression of Secondary Flows in a Mixed-Flow Pump Impeller by Application of 3D Inverse Design Method: Part 1-Design and Numerical Validation," ASME Paper 94-G T-45. 

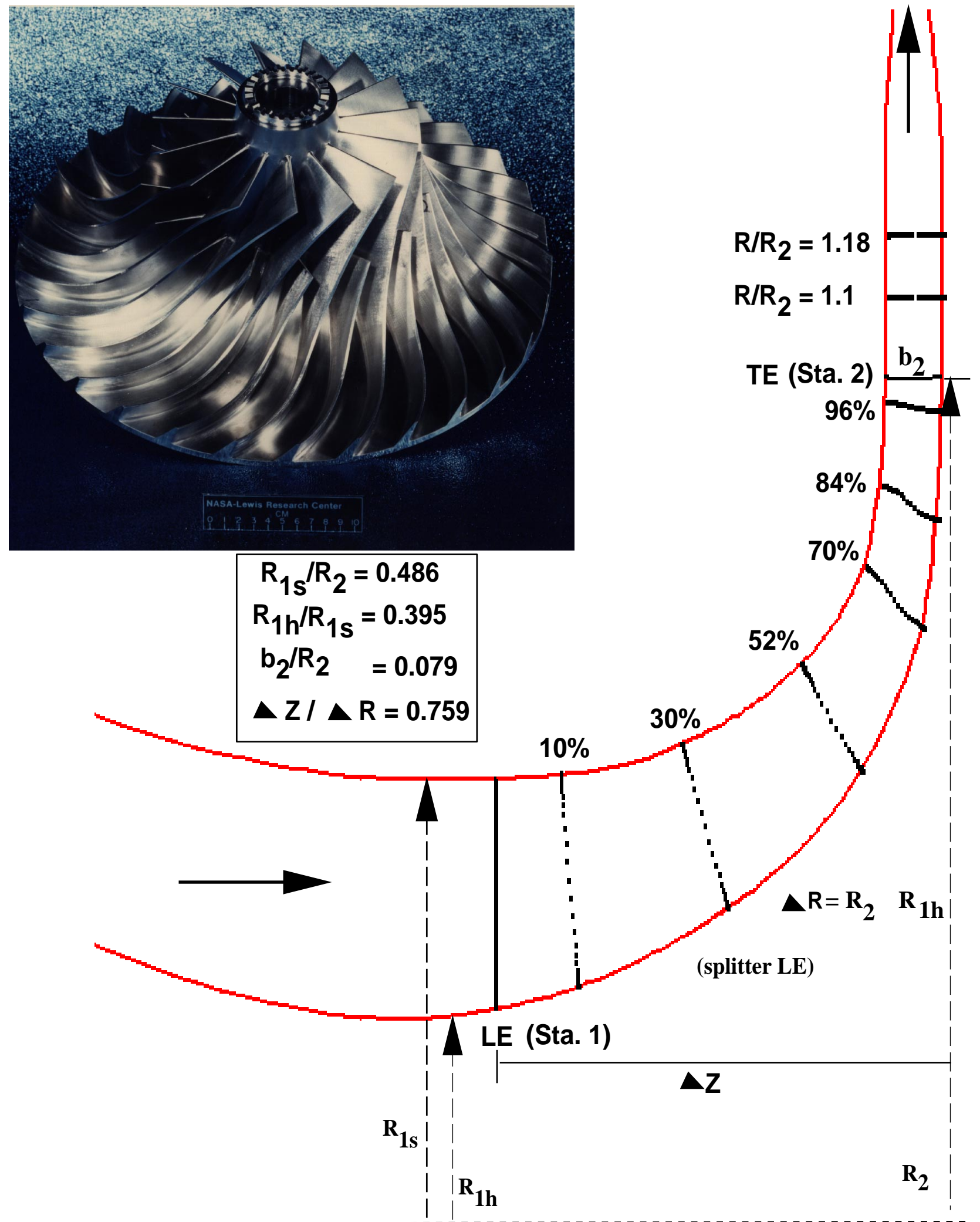

Fig. 1- Illustration of impeller blading, flowpath, and reporting stations 


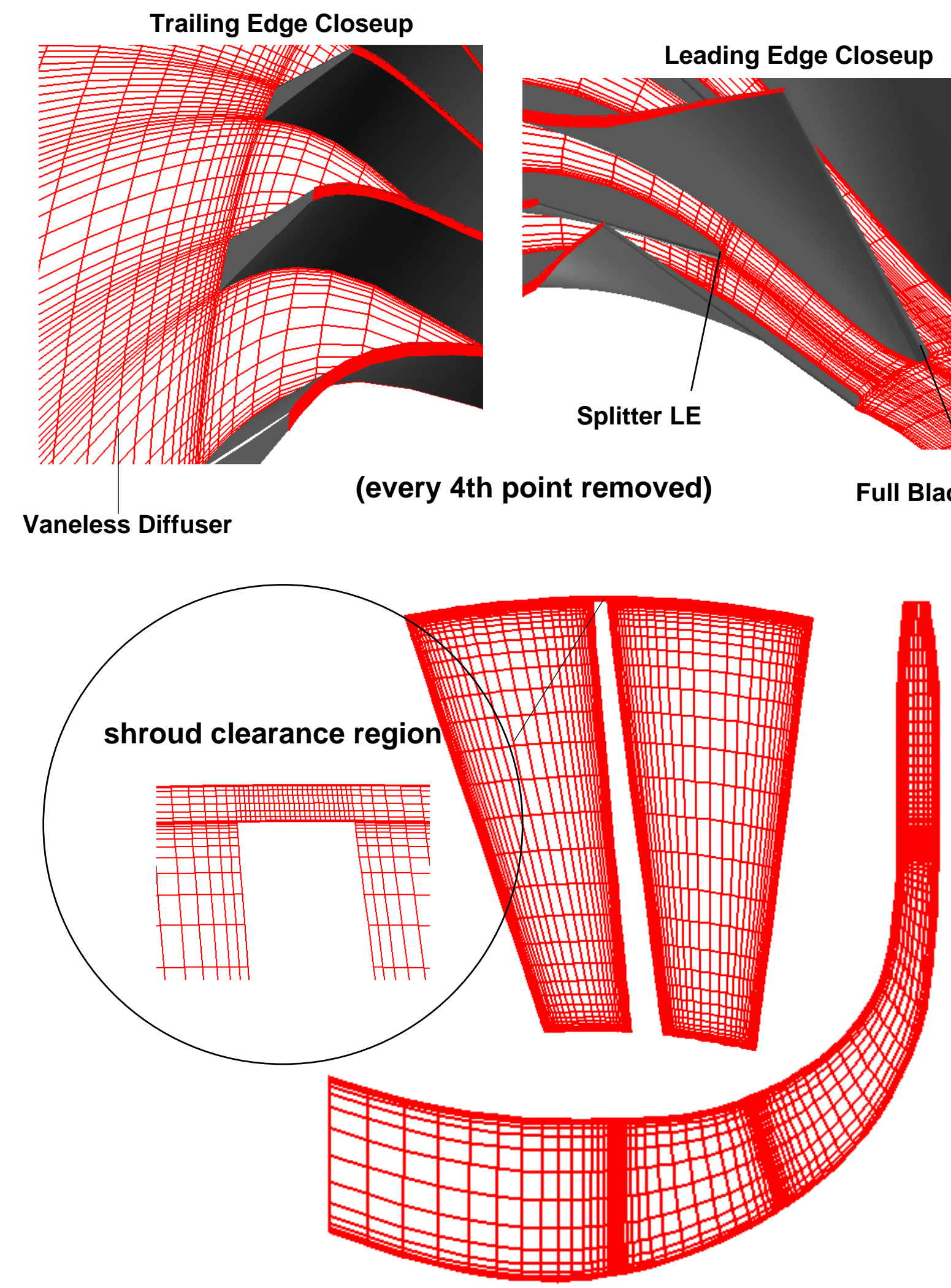

Fig. 2- Computational mesh of impeller discharging into vaneless diffuser showing closeups of impeller leading and trailing edges 


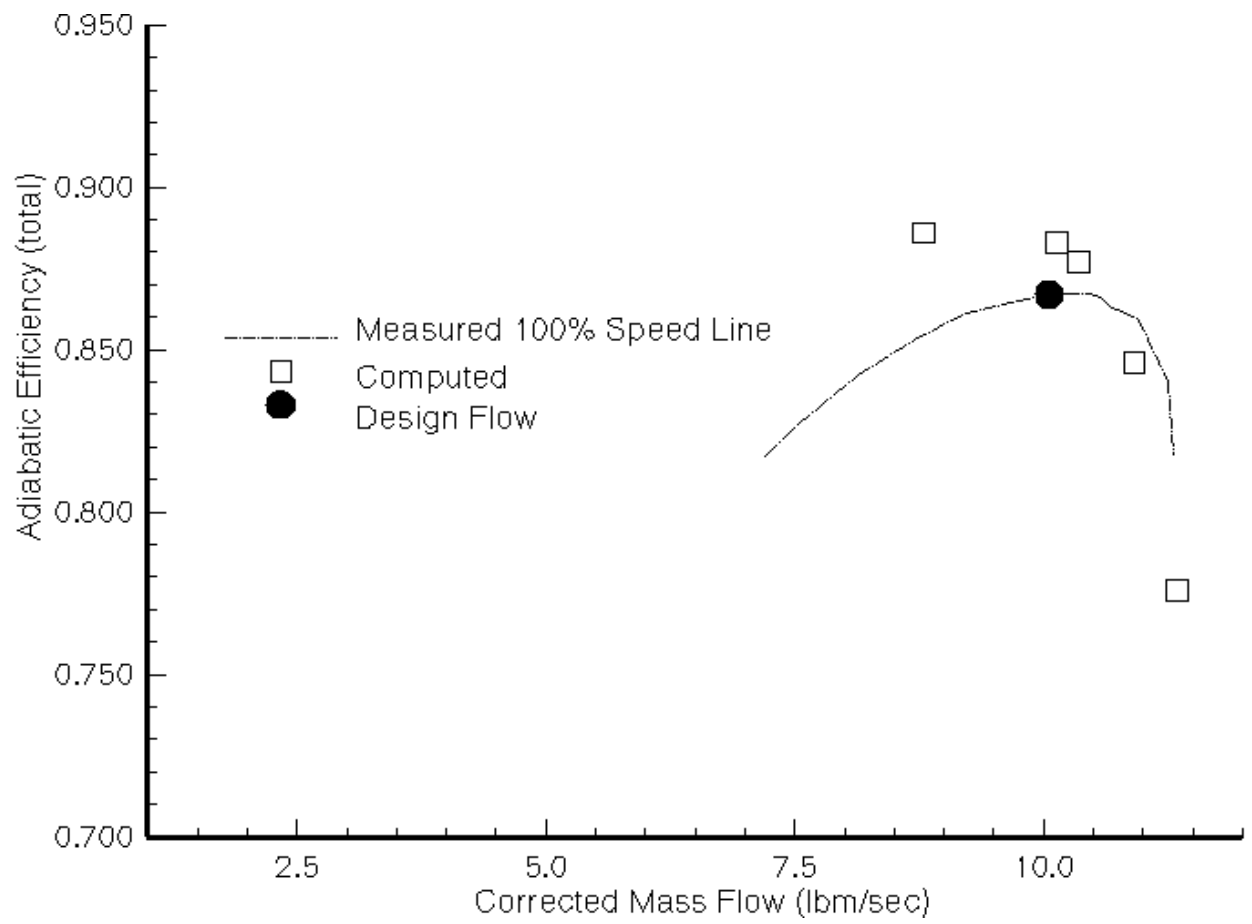

(b) Adiabatic efficiency (total to total)

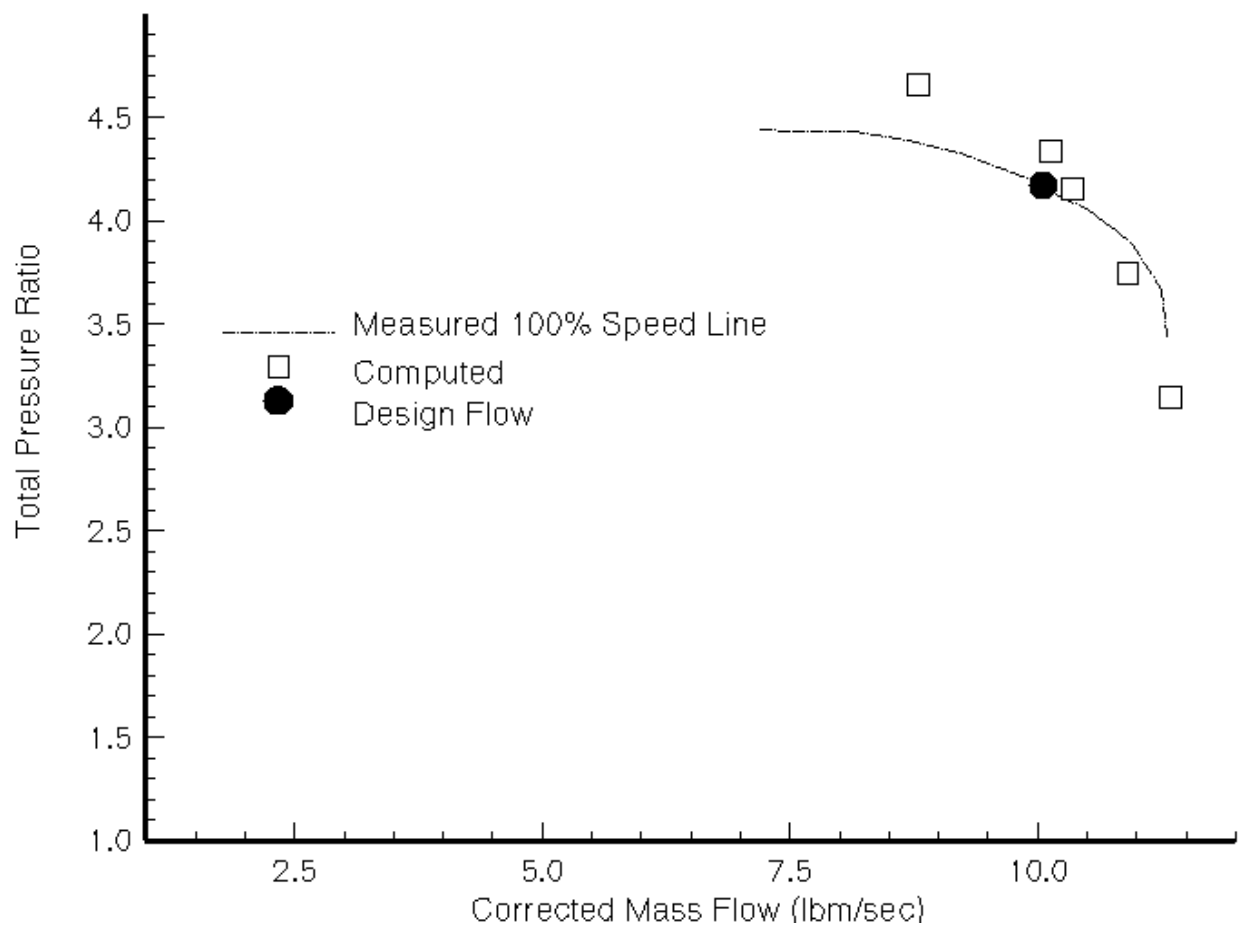

(a) Total pressure ratio

Fig. 3- Overall performance: design speed characteristic from inlet to $R / \mathbf{R}_{\mathbf{2}}=\mathbf{1 . 1 8}$ 


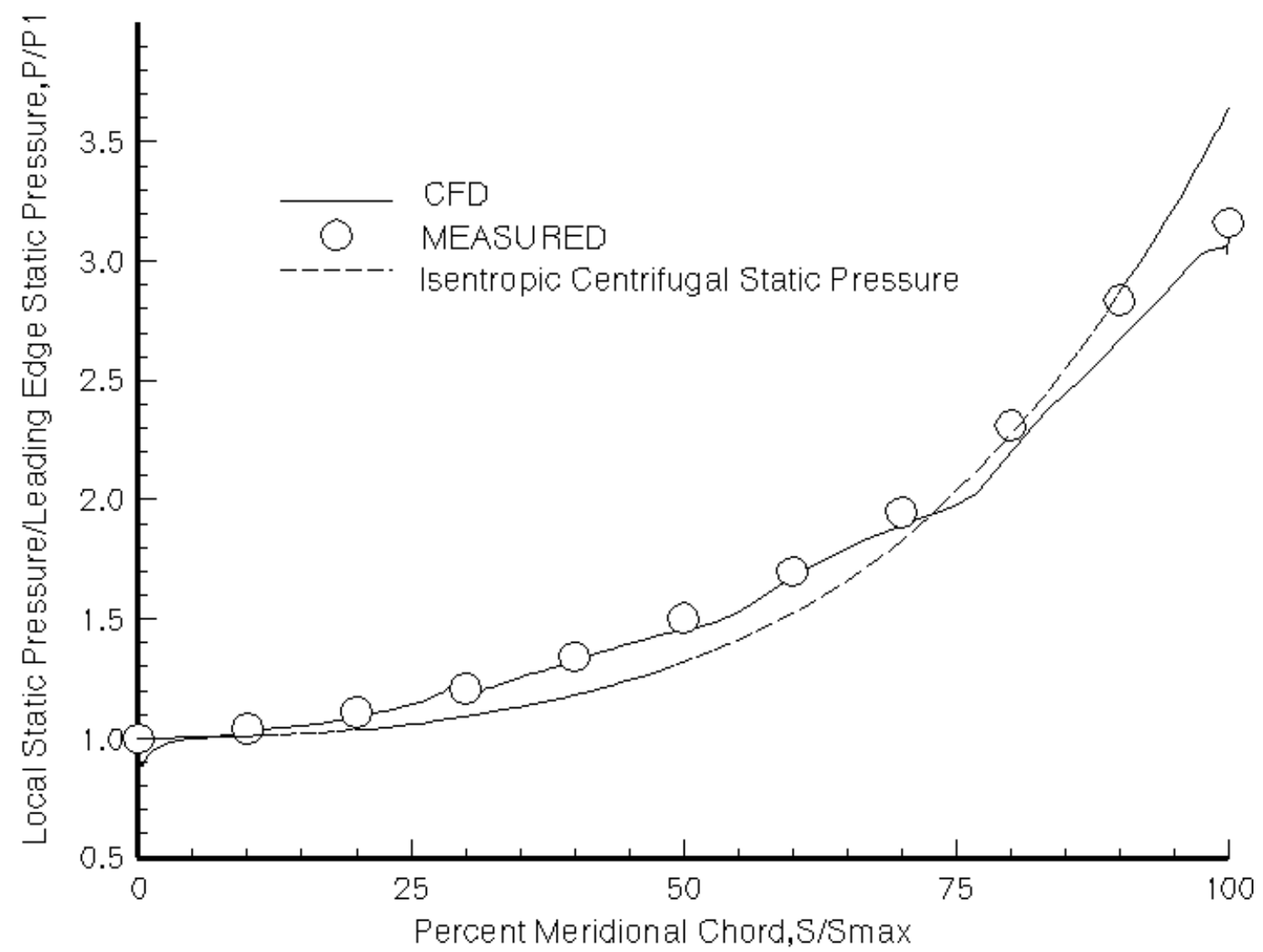

Fig. 4- Circumferentially averaged static pressure distribution along the shroud at design operation 


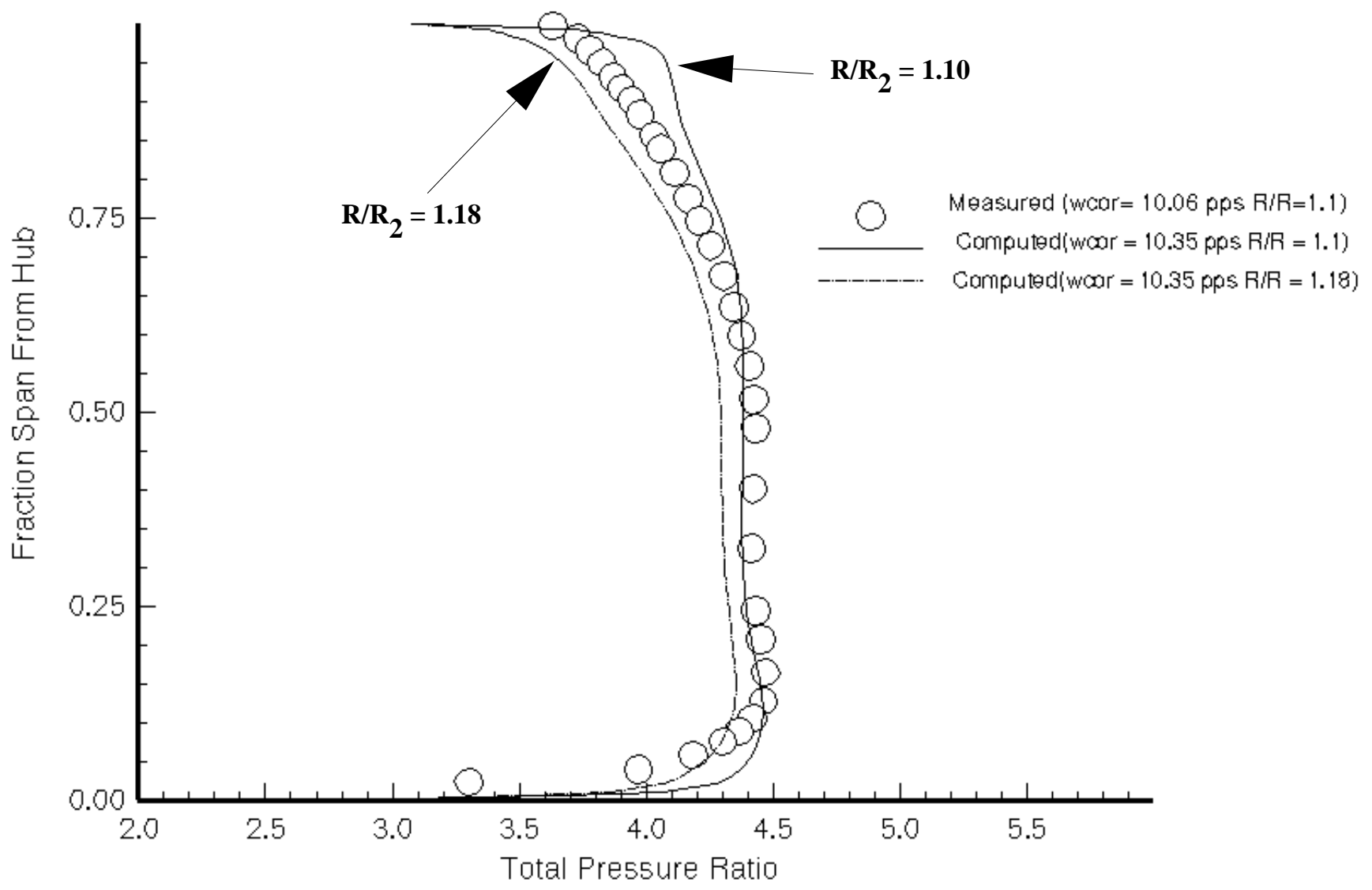

Fig. 5- Impeller exit spanwise distribution of circumferentially averaged total pressure at design operation (measurements at $R / R_{2}=1.1$ ) 


\section{CFD}

\section{Variable Tip Gap}
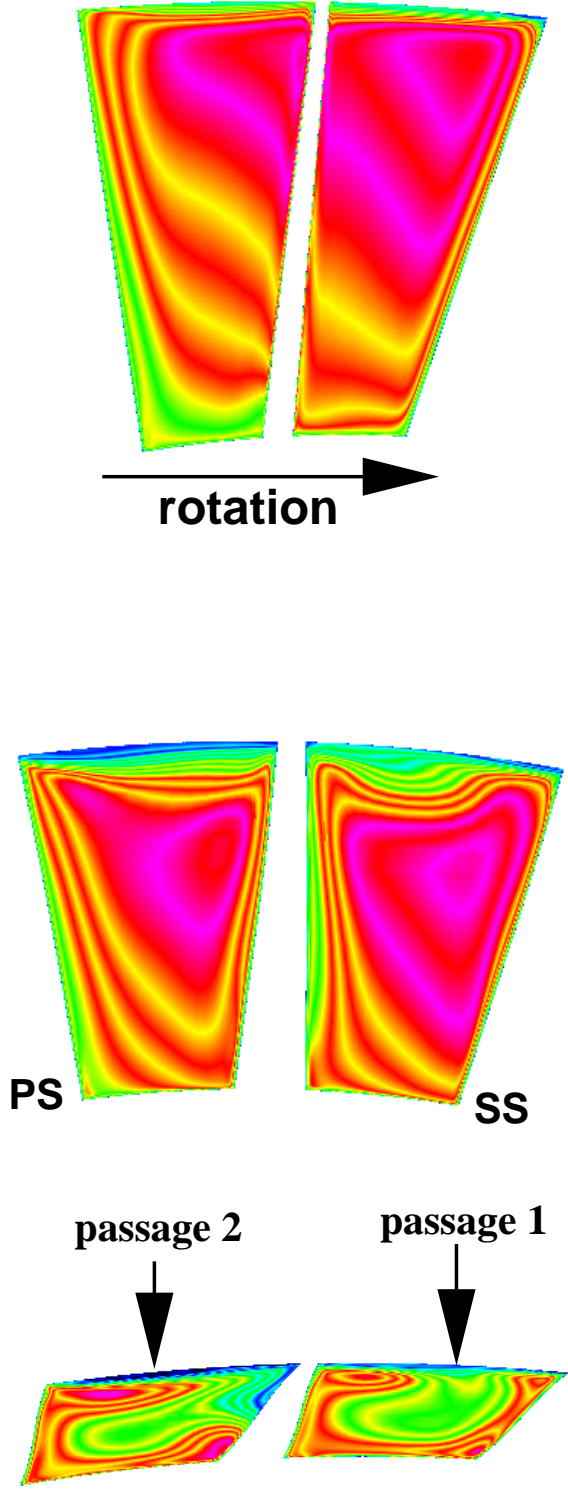

\section{Constant Tip Gap}

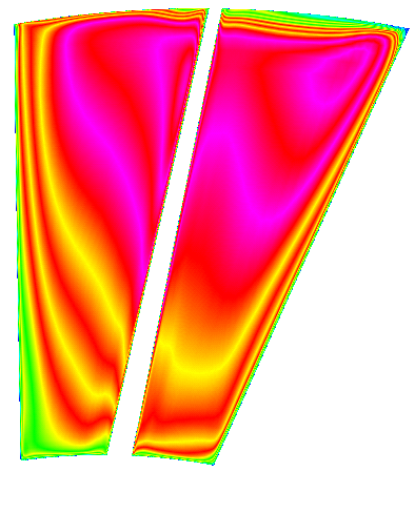

$30 \%$ Chord
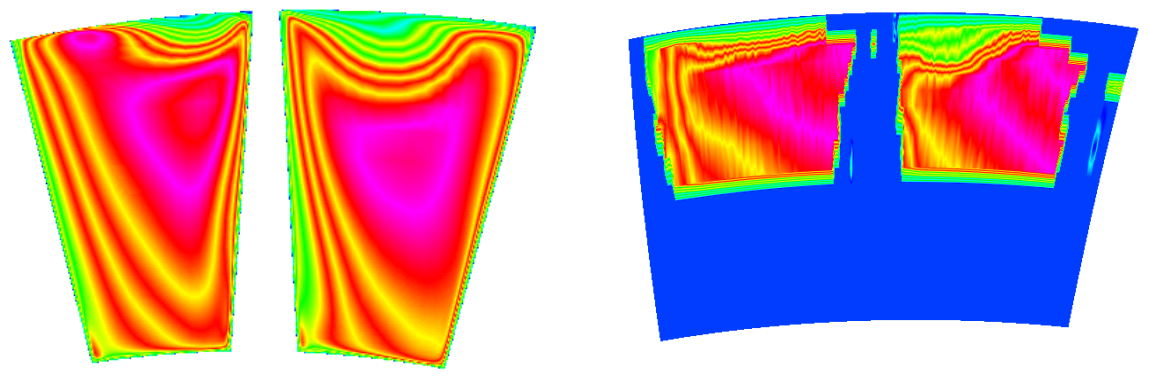
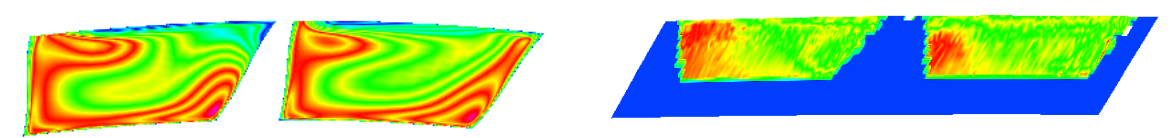

$96 \%$ Chord

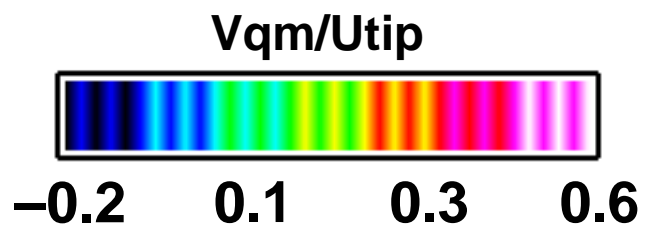

Fig. 6- Development of quasi throughflow velocity within the impeller at design condition 

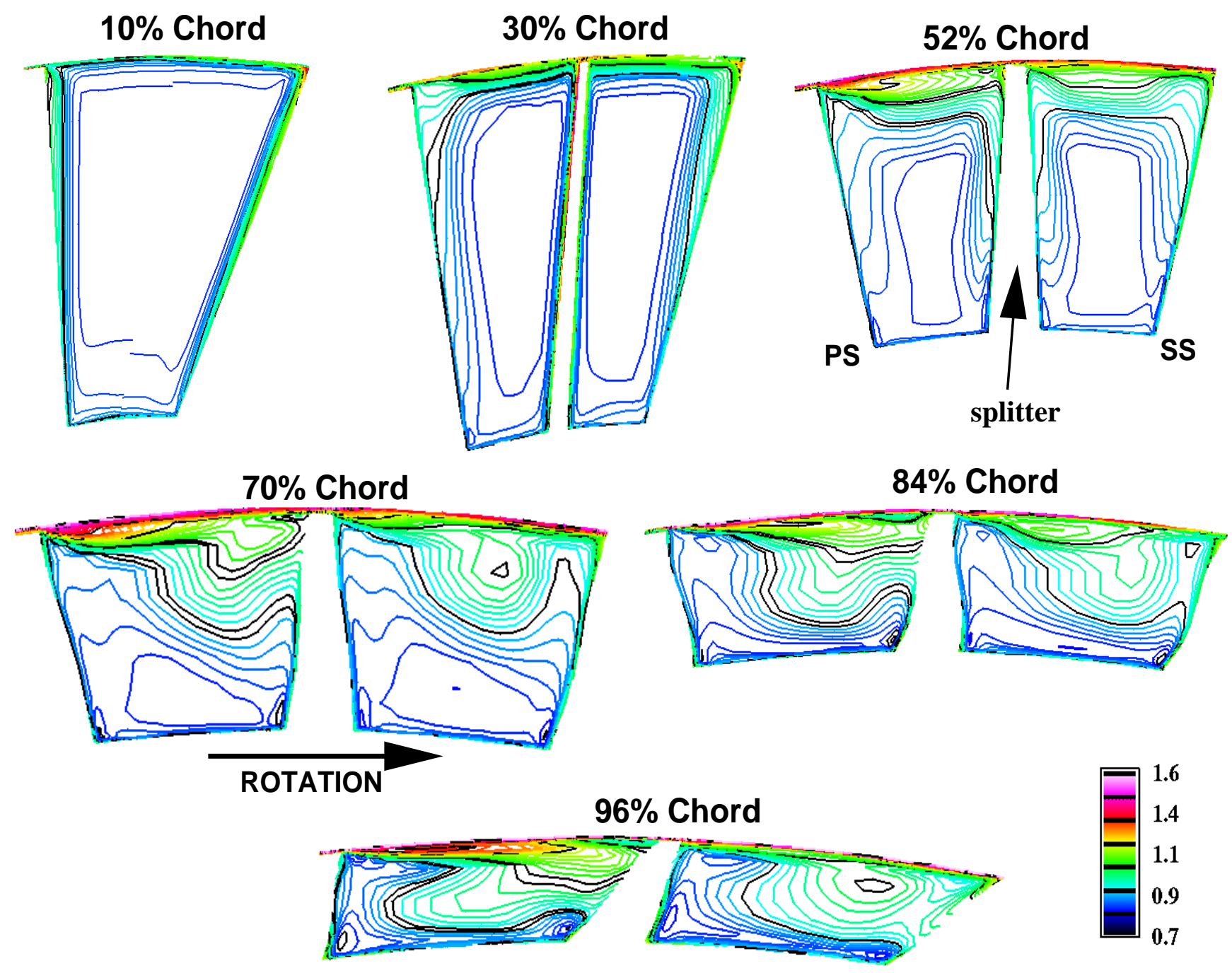
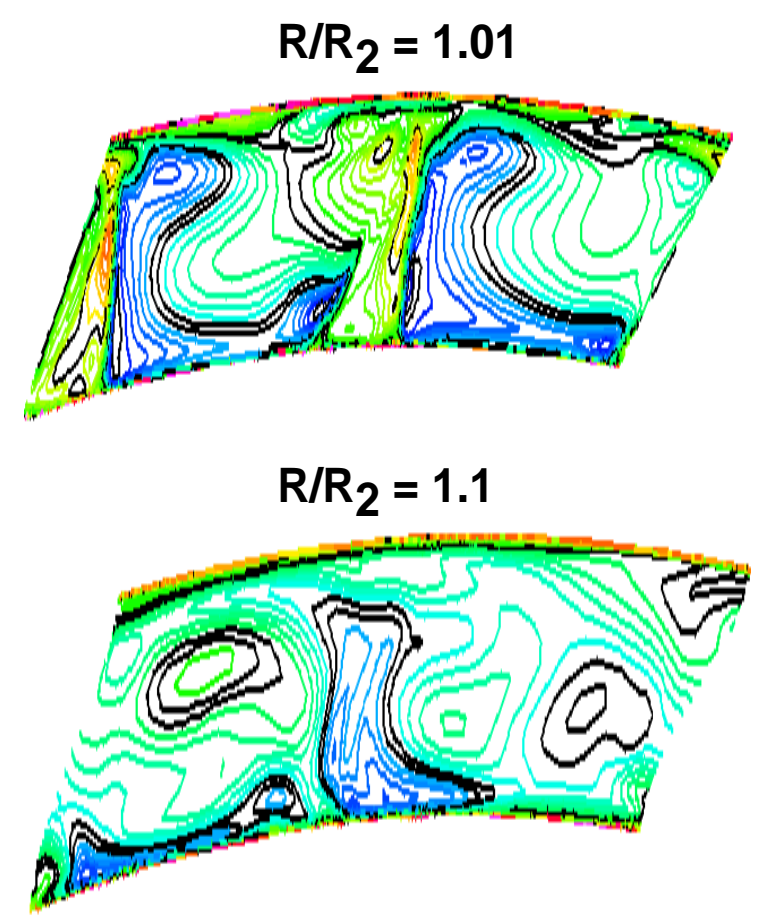

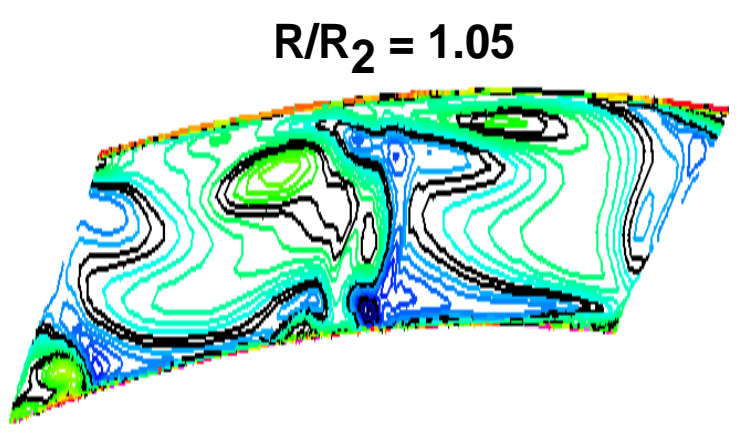

$R / R_{2}=1.18$

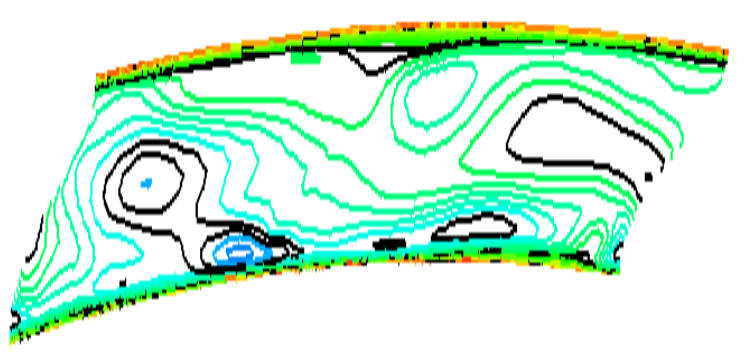

Fig. 7- Computed entropy distribution within impeller and vaneless space at design operation 


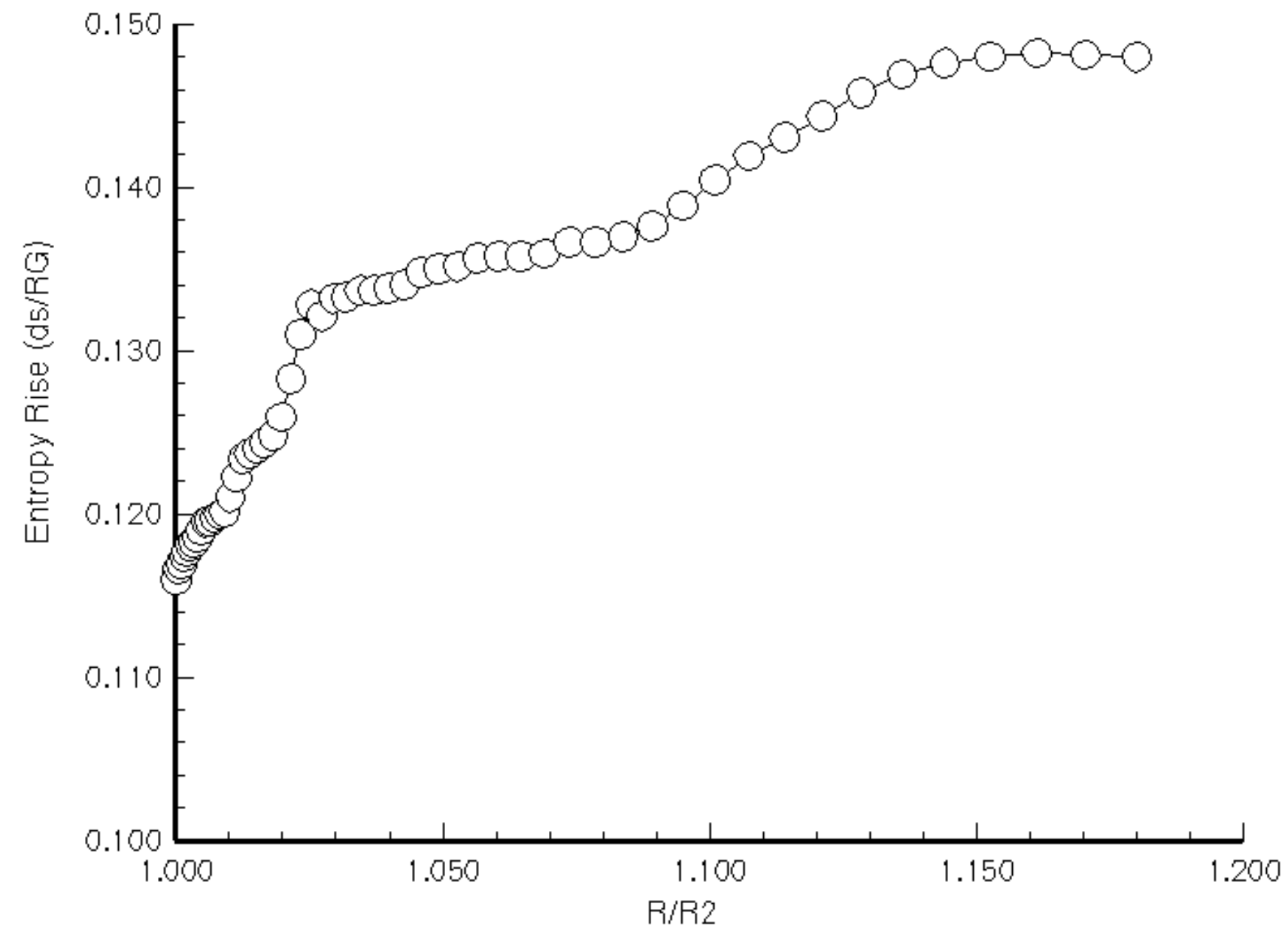

Radius Ratio

Fig. 8- Development of mass-averaged entropy change within the vaneless space as computed from CFD results at the near design operating condition 

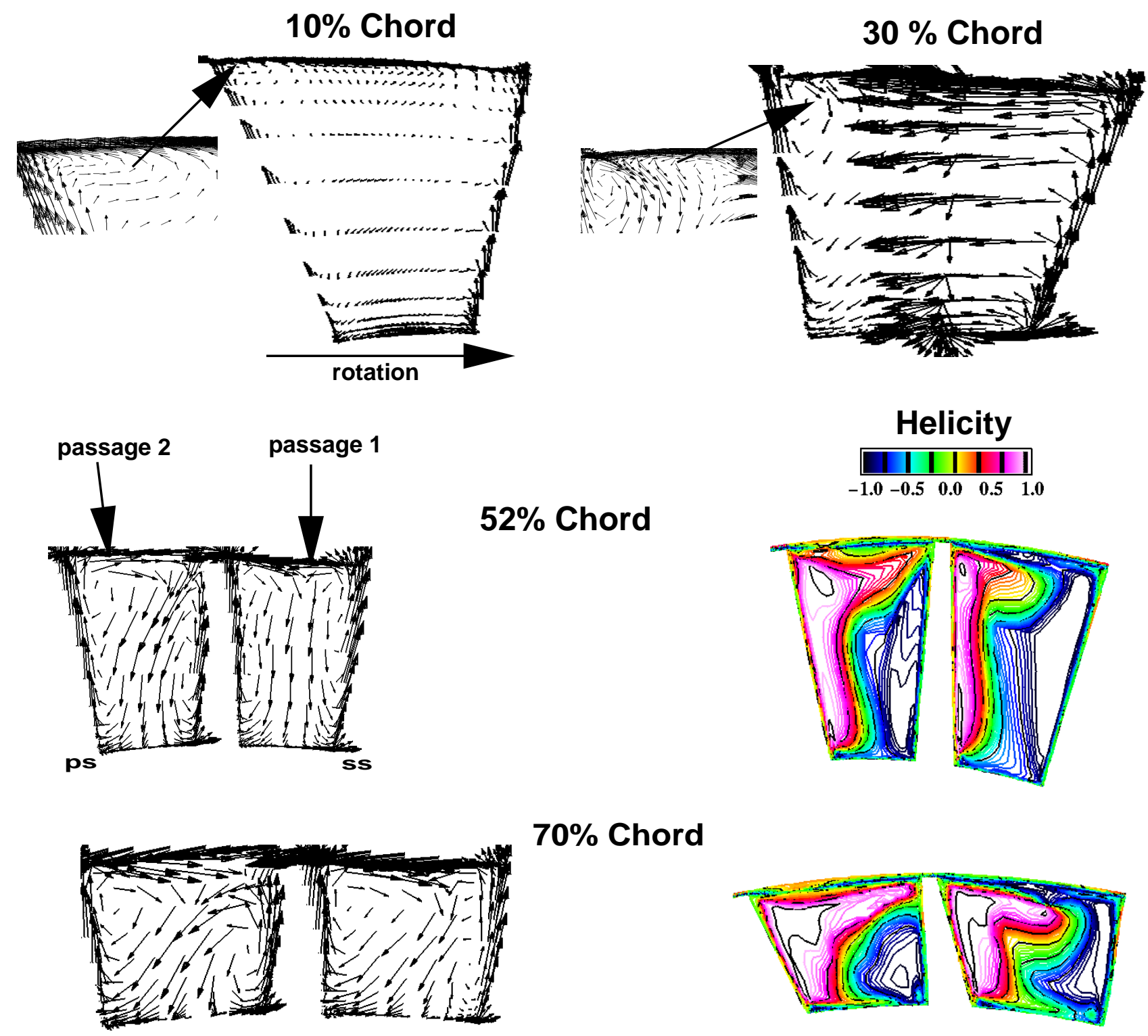

$70 \%$ Chord

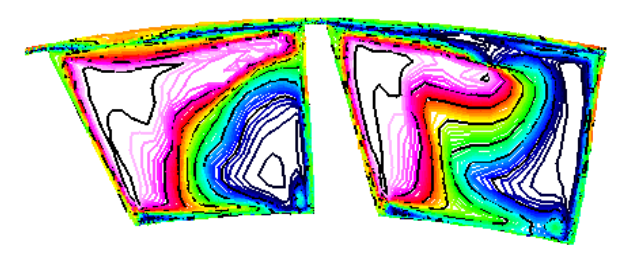

$84 \%$ Chord
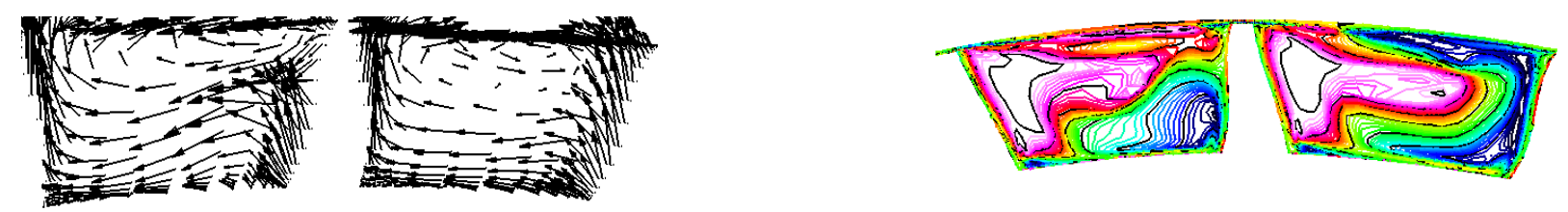

\section{6\% Chord}
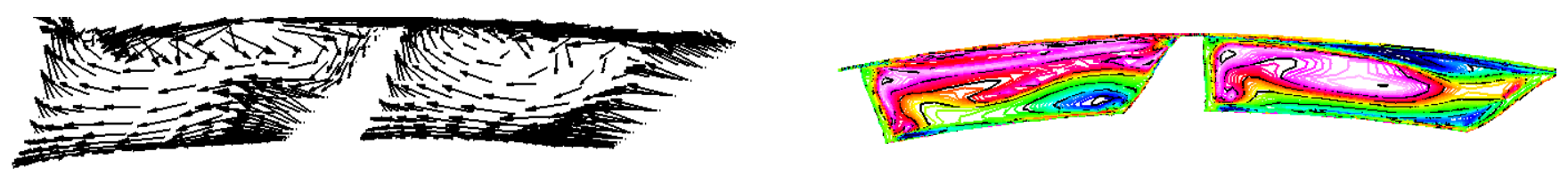

Fig. 9- Secondary flow development within the impeller at design operation 


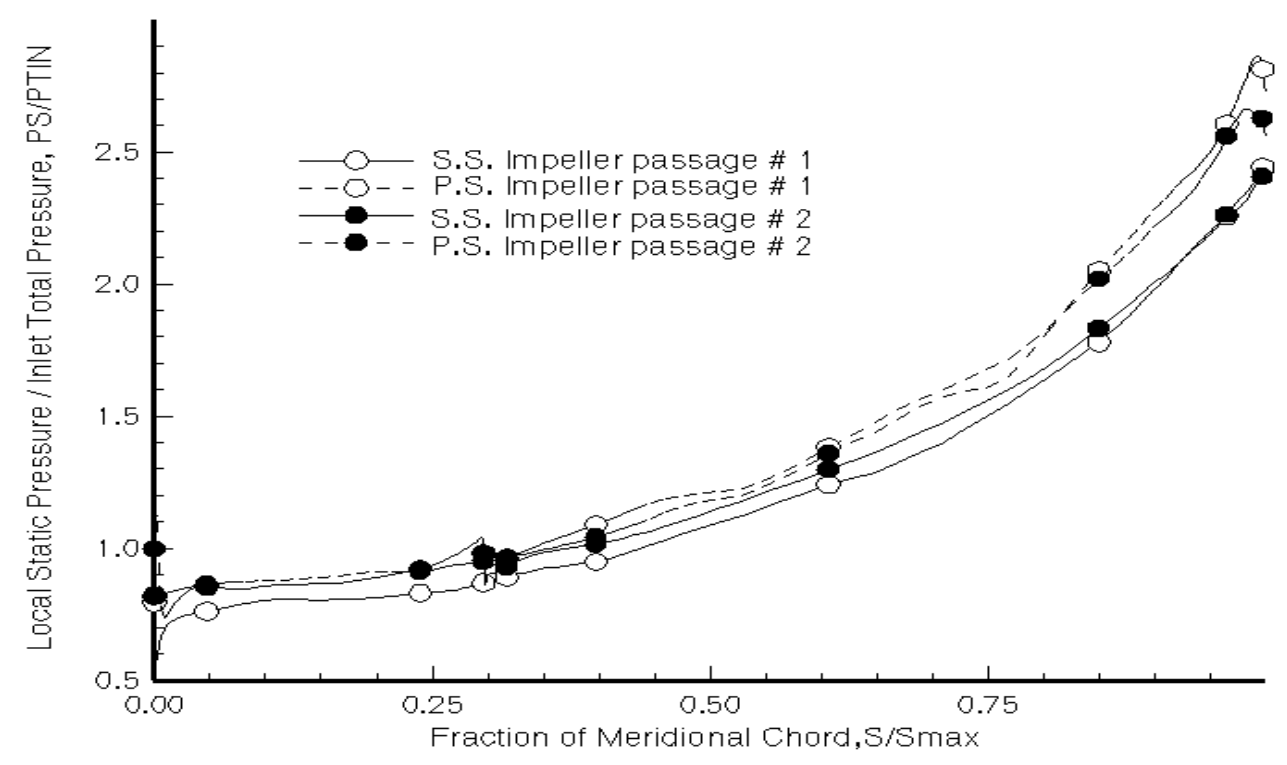

(c) ImpellerTip

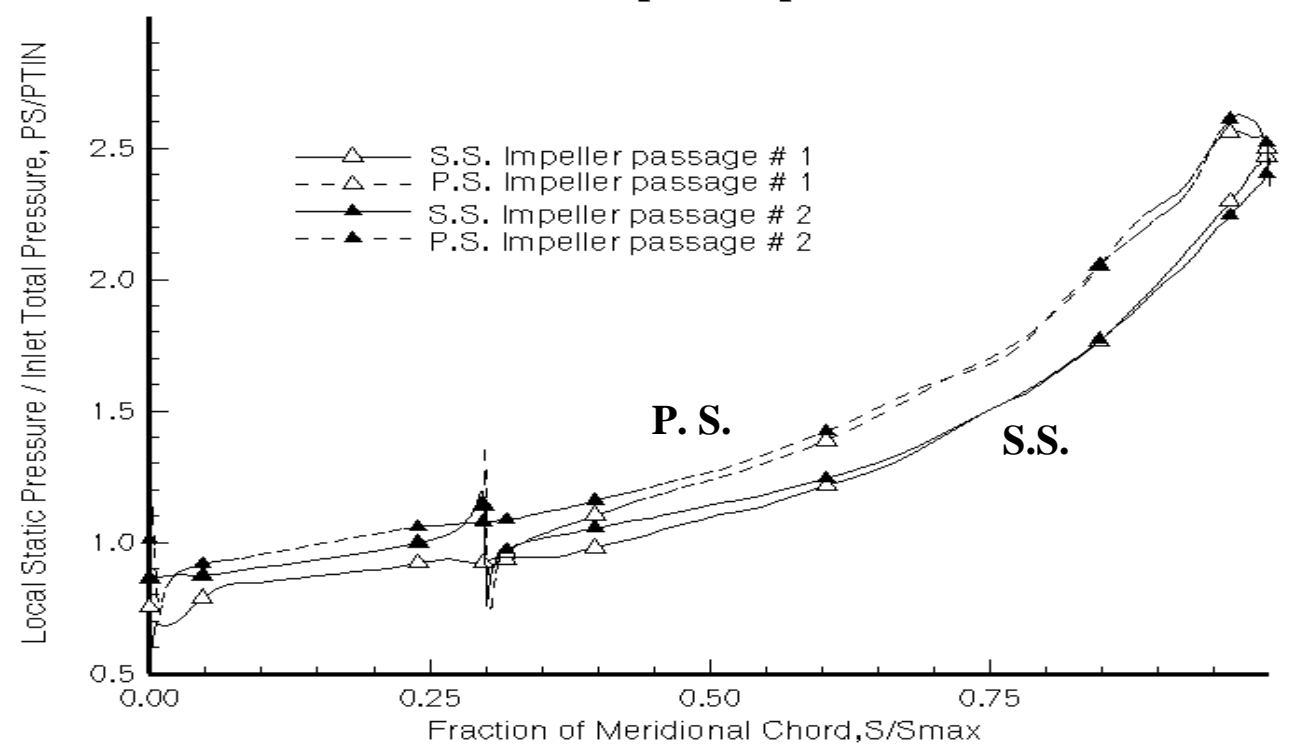

(b) Mean

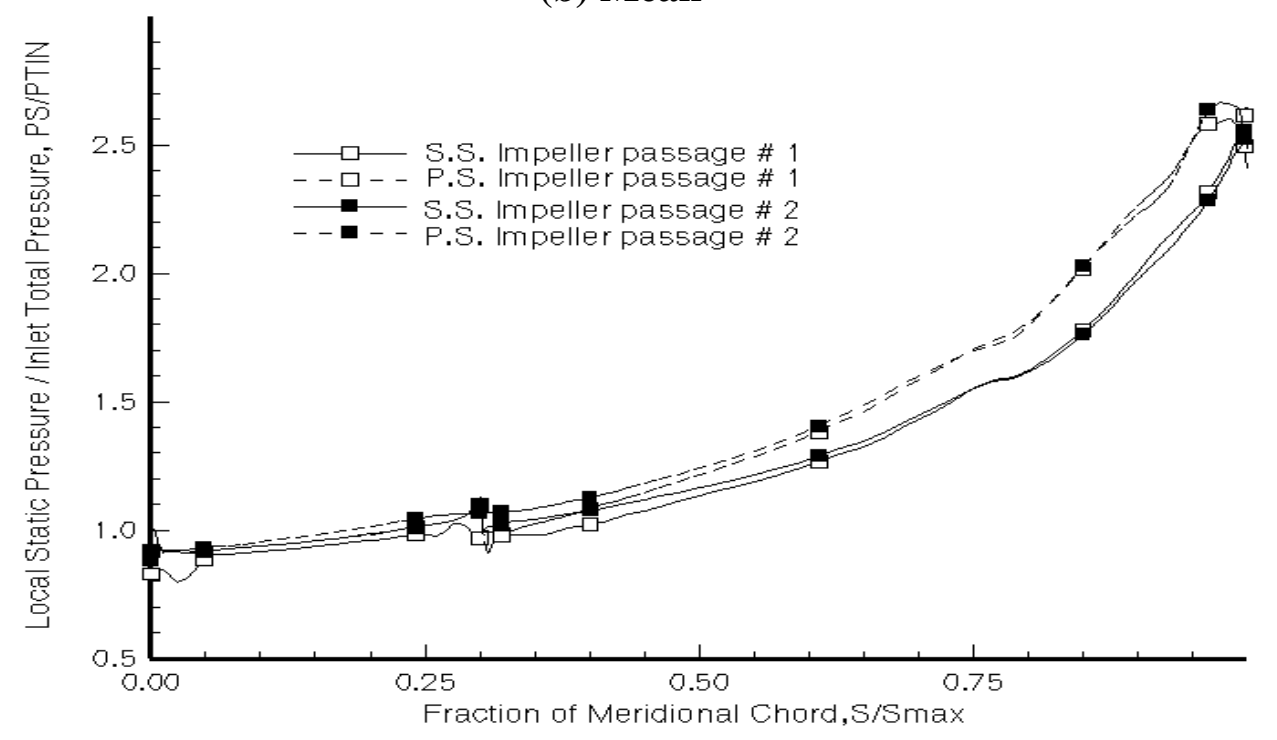

(a) Hub

Fig. 10- Computed blade static pressure loading at near design operation 


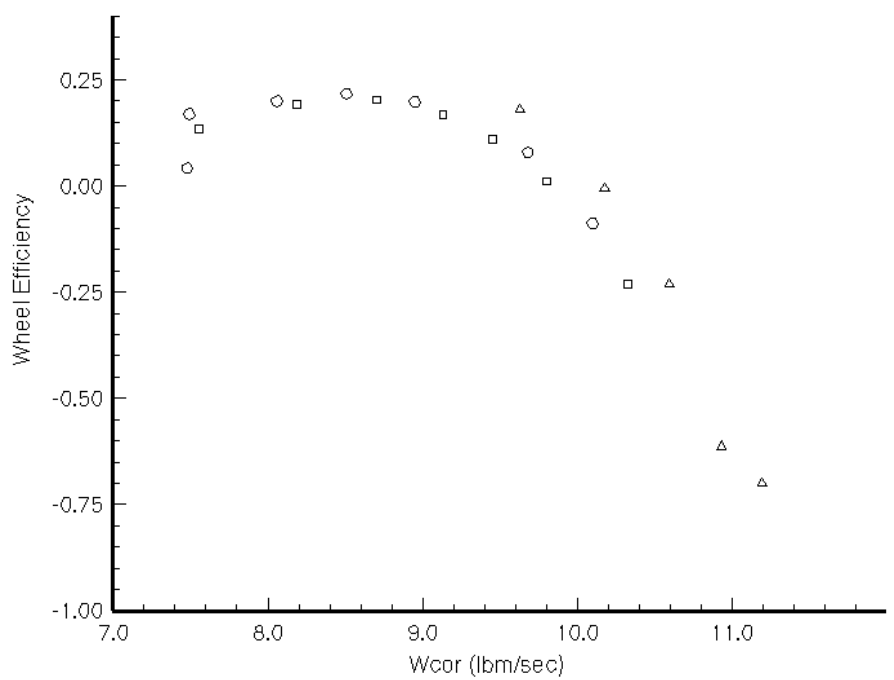

(c) Wheel efficiency

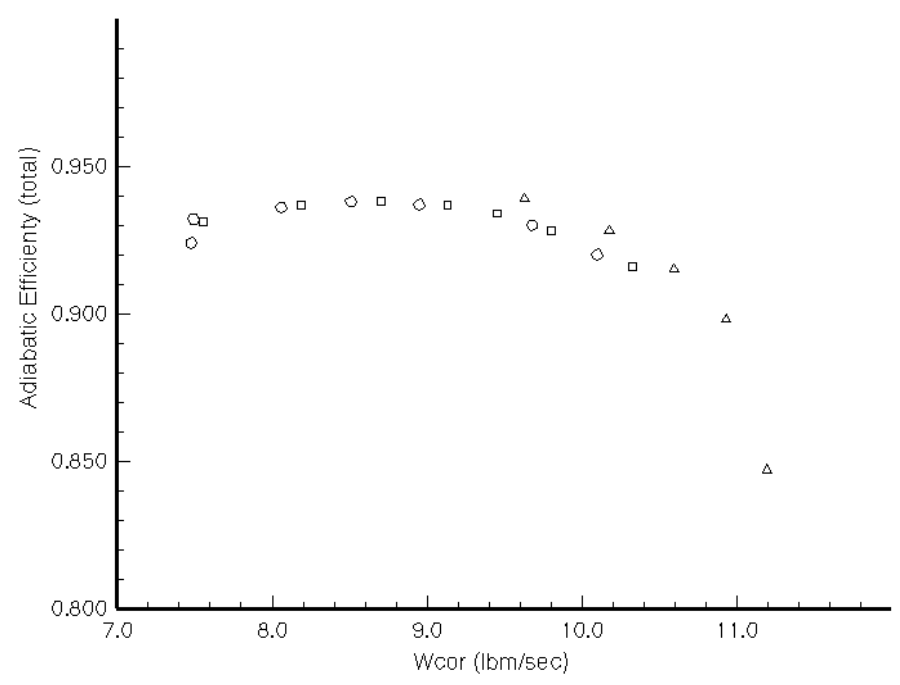

(b) Adiabatic efficiency (total)

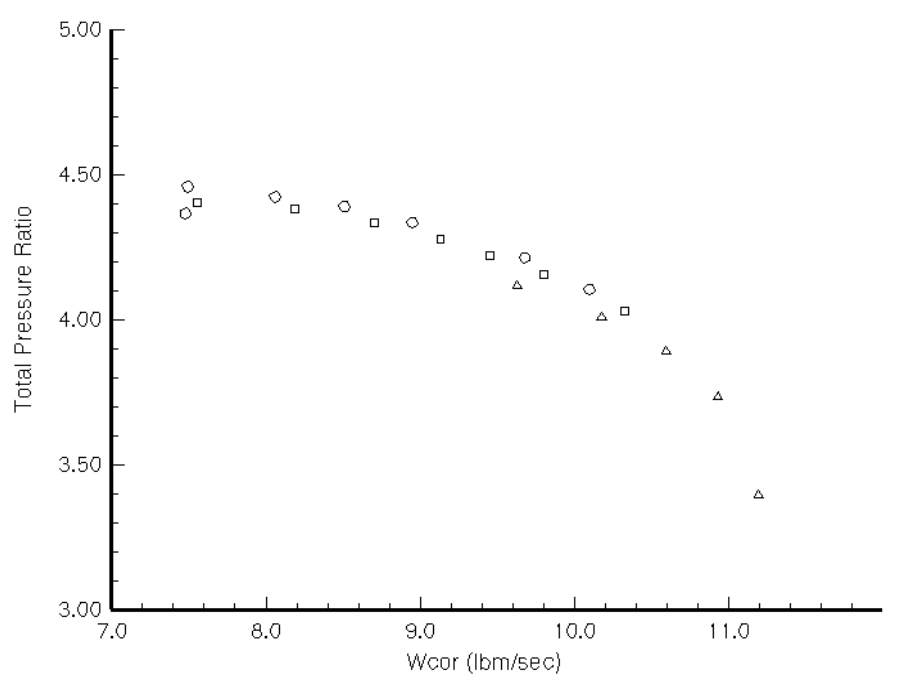

(a) Total pressure ratio

Fig. 11- Impeller performance at design speed for various corrected flows (Wcor) as derived from measured trailing edge shroud static pressure and overall total temperature at $R / \mathbf{R}_{\mathbf{2}}=1.18$ 


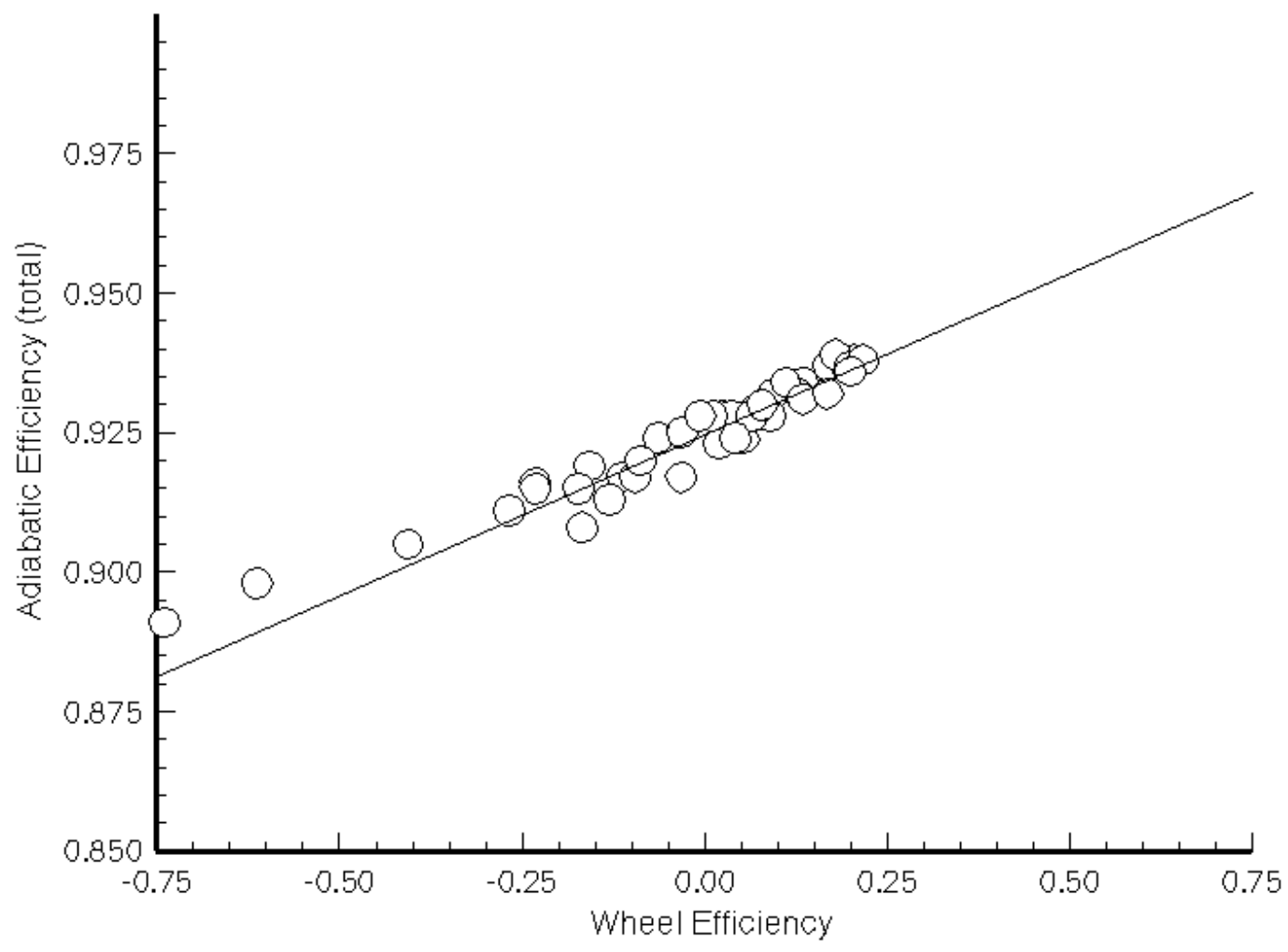

Fig. 12- Variation of impeller adiabatic efficiency with wheel efficiency as derived from measured shroud static pressure and overall total temperature ratio 
Public reporting burden for this collection of information is estimated to average 1 hour per response, including the time for reviewing instructions, searching existing data sources, gathering and maintaining the data needed, and completing and reviewing the collection of information. Send comments regarding this burden estimate or any other aspect of this collection of information, including suggestions for reducing this burden, to Washington Headquarters Services, Directorate for Information Operations and Reports, 1215 Jefferson Davis Highway, Suite 1204, Arlington, VA 22202-4302, and to the Office of Management and Budget, Paperwork Reduction Project (0704-0188), Washington, DC 20503.

\begin{tabular}{|l|c|r|}
\hline 1. AGENCY USE ONLY (Leave blank) & 2. REPORT DATE & 3. REPORT TYPE AND DATES COVERED \\
July 1997 & Technical Memorandum
\end{tabular}

\section{TITLE AND SUBTITLE}

Aerodynamic Synthesis of a Centrifugal Impeller Using CFD and Measurements

L.M. Larosiliere, G.J. Skoch, and P.S. Prahst
5. FUNDING NUMBERS

WU-523-22-13

8. PERFORMING ORGANIZATION REPORT NUMBER

E-10818

10. SPONSORING/MONITORING AGENCY REPORT NUMBER

NASA TM-107515

ARL-TR-1461

AIAA-97-2878

U.S. Army Research Laboratory

Adelphi, Maryland 20783-1145

\section{SUPPLEMENTARY NOTES}

Prepared for the 33rd Joint Propulsion Conference and Exhibit cosponsored by AIAA, ASME, SAE, and ASEE, Seattle, Washington, July 6-9, 1997. L.M. Larosiliere and G.J. Skoch, U.S. Army Research Laboratory, Lewis Research Center, Cleveland, Ohio 44135; P.S. Prahst, NYMA, Inc., 2001 Aerospace Parkway, Brook Park, Ohio 44142 (work funded by NASA Contract NAS3-27186). Responsible person, L.M. Larosiliere, organization code 5810, (216) 433-3403.

\begin{tabular}{l|l} 
12a. DISTRIBUTION/AVAILABILITY STATEMENT & 12b. DISTRIBUTION CODE
\end{tabular}

Unclassified - Unlimited

Subject Category 07

This publication is available from the NASA Center for AeroSpace Information, (301) 621-0390.

13. ABSTRACT (Maximum 200 words)

The performance and flow structure in an unshrouded impeller of approximately $4: 1$ pressure ratio is synthesized on the basis of a detailed analysis of 3D viscous CFD results and aerodynamic measurements. A good data match was obtained between CFD and measurements using laser anemometry and pneumatic probes. This solidified the role of the CFD model as a reliable representation of the impeller internal flow structure and integrated performance. Results are presented showing the loss production and secondary flow structure in the impeller. The results indicate that while the overall impeller efficiency is high, the impeller shroud static pressure recovery potential is underdeveloped leading to a performance degradation in the downstream diffusing element. Thus, a case is made for a follow-on impeller parametric design study to improve the flow quality. A strategy for aerodynamic performance enhancement is outlined and an estimate of the gain in overall impeller efficiency that might be realized through improvements to the relative diffusion process is provided.

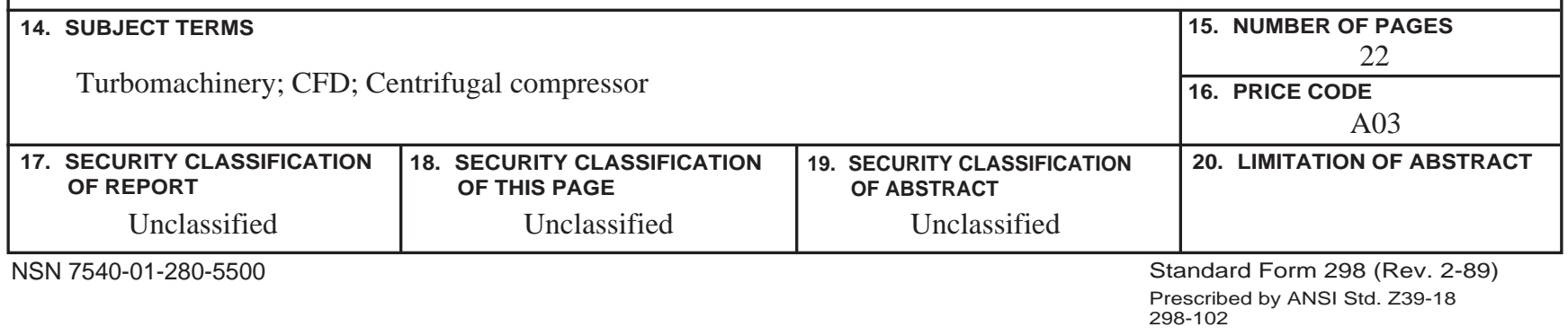

